Journal of Material Culture

2012 17: 103-110

The online version of this article can be found at:

DOI: $10.1177 / 1359183511433259$

\title{
Placing and tracing absence: A material culture of the immaterial
}

\author{
Morgan Meyer
}

\begin{abstract}
This essay engages with recent work on an unusual, yet fascinating theme: absence. Two edited collections have recently been published that deal with the topic: An Anthropology of Absence: Materializations of Transcendence and Loss (Bille et al., 2010) and The Matter of Death: Space, Place and Materiality (Hockey et al., 2010). These books explore an almost counterintuitive aspect of absence: its material culture. Indeed, absence has a materiality and exists in - and has effects on - the spaces people inhabit and their daily practices and experiences. Drawing on the discussions in these two books and on other recent developments in the study of absence, this essay considers the relational ontology of absence, conceiving absence not as a thing in itself but as something that exists through relations that give absence matter. Absence, in this view, is something performed, textured and materialized through relations and processes, and via objects. We therefore need to trace absence. This entails following and describing the processes through which absence becomes matter and absence comes to matter. It means to map out, locate and follow the traces of absence and understand absences as traces, that is, as residual, incomplete, elusive, ambiguous, yet material entities.
\end{abstract}

\section{Keywords}

absence/presence, materiality, relational ontology of absence, tracing absence

Absence comes in various guises. Phantom pains, deceased people, ancestors, destroyed buildings, ghosts, gods, silences ... All these absences can have effects on our lives. They matter. They are, in certain places and at certain times, turned into matter: into objects, texts, pictures, and so on. This essay is concerned with absences by seeking to answer the following question: how and where does absence come to matter? In other words, how is absence performed, materialized and objectified? In and through which kinds of tools, objects, representations and spaces is absence made present? 
Although work on absence is rather rare and dispersed, there have been some recent texts and developments in this area that call for a more programmatic and focused engagement. This review essay considers two recent books that have contributed to these developments and are concerned with absence. It further considers them in relation to other relevant texts, such as the work of Kevin Hetherington (2003, 2004). Two strands of arguments are pursued: first, ideas around the materiality and agency of absence; and, second, the related argument that absence is something that is 'placed' and that needs to be 'traced' and leaves 'traces'.

\section{The materiality and agency of absence}

Absences matter. The way in which they do is one of the key questions explored in the book An Anthropology of Absence: Materializations of Transcendence and Loss (Bille et al., 2010, referenced as AA hereafter). The introduction sets the scene: 'what may be materially absent still influences people's experience of the material world' (p. 4) The editors' starting assumption is that 'absence ... may have just as much effect as material presence ... We thus take absence to be as much of an occurrence in real life as presence' (p. 10). Drawing mainly on the disciplines of anthropology and archaeology, the various chapters of the book tell stories of present absences in various forms: pictures of deceased people, inscriptions on graves, absence of knowledge and materializations of a tsunami disaster. We learn that the absent is made present through talk and texts, through thoughts and things. One of the key messages to take from the book is that it is via various kind of places, objects and practices that the absent can have an important effect on the social world - in other words, that absence has agency. This argument resonates with a key text by Kevin Hetherington (2004: 159), in which he argues that:

The absent can have just as much of an effect upon relations as recognisable forms of presence can have. Social relations are performed not only around what is there but sometimes also around the presence of what is not ... Indeed, the category of absence can have a significant presence in social relations and in material culture. (emphasis in original)

In other words, absence does things, it is performative. Fowles (2010: 28, in AA) puts it this way: 'Absences push back and resist. They prompt us into action. And like present things, absences also have their distinctive affordances and material consequences.'

Yet absence is not only something that does. Absence is also something we engage with, something we do something to. In comparing cemeteries and museums, Meyer and Woodthorpe (2008) note:

In a museum and a cemetery we can 'feel', 'see', and 'hear' absence. In cemeteries, we are confronted with absence in the loss of people ... In museums, we are confronted with the absence of the 'world out there' and/or the 'world that once was'. Both sites, hence, do something to and something with the absent transforming, freezing, materialising, evoking, delineating, enacting, performing, and remembering the absent. 
There are various public and private practices concerned with 'presencing absence'. One important group of professionals whose activities are directly concerned with making the absent present are archaeologists. Buchli and Lucas (2001: 173) write: 'The presencing of absence, that is, its materialisation through the archaeological act, makes things "matter".'

This brings us to the second book, The Matter of Death: Space, Place and Materiality (Hockey et al., 2010; referenced as MD hereafter), which looks at the material culture of death, that is: "the stuff, the spaces, the practices which surround the ending of embodied life, the disposal of the body, the mourning and memorialisation which then ensue' (p. 16). In so doing, the book takes us to a variety of spaces where we encounter death: hospitals, residential homes, cemeteries, burial grounds, roadside memorials, sites where ashes are scattered. One chapter of the book even takes us to the imagined terrains of deities and spirits, or 'spaces of spirits': séances with mediums, temples, churches, shrines, pyramids, and sky burials. As the author of the chapter tells us 'spirits would not be the spirits they are without the places devised for their "presence"' (Davies, 2010: 212, in MD), arguing that these spaces have economic and political dimensions.

All in all, it is the materially grounded nature - the spaces, places, bodies, objects, architectures, equipments - of the human experiences and practices related to death that are explored in great detail in MD. For example, we learn about the many 'things' we find associated with death and on people's graves: flowers and plants, wind chimes, gnomes, glass ornaments, letters and cards, toys, mementos, ceramic mushrooms, solarpowered frogs (see the chapters by Bleyen and Woodthorpe in MD). One object, for instance, that powerfully evokes death is the 'spirit mask' of dead people used by the Melanesian Rauto during memorial dances. This spirit mask "'brings back to life" a representation of the dead, with personal memories evoked once more' (Davies, 2010: 212, in MD). Similarly, in AA, several chapters describe the various objects put on, or next to, graves, whether they are plants, candles, or stones. Two things are important to stress here: first, that people take 'care' of graves and objects; and, second, that the immateriality of the deceased may be 're-formulated and achieve serious immediacy and presence' by being subjectified and materialized through such objects (Sørensen, 2010: 118, 128, in AA; see also Hetherington, 2004: 171 on the notion of care for the absent). In her captivating chapter about the Asian tsunami disaster in 2004, Hastrup (2010: 100, in AA) examines a memorial monument and various 'scarred objects'; she argues that 'missing, broken or unfinished artefacts and their ambiguous nature as both present and absent, served as common materializations of loss and seemed to function as a means for the survivors to reclaim their everyday life in the aftermath of the disaster.'

However, we must be careful not to conflate absence and materiality. For absences are 'part of the material world', but also 'foreign to that world' (Fowles, 2010: 39, in AA). Absence turned into matter is necessarily uncertain, unstable matter. It is difficult, perhaps impossible, to stabilize, formalize, or define absence. For absence is, by its nature, unattainable, unstable, not present - hence the paradoxical nature of any discussion about the materiality of absence, an issue raised in several chapters in both books. Perhaps one way to overcome this paradox and the 'ambiguous materiality' of absence is to think of absence as an 'immaterial thing' or 'more than immaterial and less than material' (Bille, 2010: 179, in AA). What is more, the focus on materiality in recent academic debates might 
have given us a 'crude notion of presence linked to physicality and tangibility' (Fowles, 2010: 25, in $A A$ ) and the risk that we too quickly equate materiality with physicality (Meskell, 2010: 207, in AA). But, conversely, we should not conflate absence with immateriality either (Buchli, 2010, in AA).

\section{Places of absence}

There are some edifices that are famous for having been partially or entirely destroyed, yet still have an enduring presence: the Berlin Wall, the Bastille in Paris, the Buddhas of Bamiyan, the city of Hiroshima, the Twin Towers in New York. Yet if there is one place that is probably most commonly associated with absence, it is the cemetery. The cemetery is an institutionalized place for memorializing absence. It is a space where we literally find the remains of those who once lived, usually underneath the ground and hidden from view. It is also an institution in the sense that we encounter professionals, explicit and implicit rules and codes of behaviour that manage and order death in a certain way within this space. (On cemeteries, see especially Woodthorpe's chapter in MD and the chapters by Renshaw and Sørensen in AA.)

This does not mean, however, that death and absence can be entirely limited to, and contained in, places and institutions such as cemeteries. As Hockey et al. (2010: 18) point out, 'death ... cannot be contained within spaces specifically and conveniently "set aside".' We are always dealing with partial containment of death (p. 233). The trajectories of ashes in the UK - from the crematorium to the diverse sites where they are finally disposed - are a telling example of the multiple destinies of human remains. Apart from the cemetery, ashes are disposed in the landscape, in water, in pubs, on football grounds; they are kept at home, sent into space, turned into diamonds ... Ashes have no simple, predetermined destinations, but their trajectories are rather open, creative, indeterminate, participative processes that take time and are fraught with hesitations. In fact, the matter and the location of ashes is important to people (Kellaher et al., 2010: 137, in MD). Another example are burials in people's own private gardens, which trigger varied reactions, some people welcoming them, others seeing them as inappropriate, tasteless, or disgusting (Walter and Gittings, 2010, in MD). What is at stake here is that the often unmarked and unbounded grave threatens the boundaries between the living and the dead, between death space and domestic space. Roadside memorials are a further example: their 'location, outside of the conventional and acceptable contexts such as cemeteries ... disrupts attempts to contain these reminders of mortality' (MacConville and McQuillan, 2010: 207, in MD). But, it must be noted, even within the cemetery the 'location' of the dead can be ambiguous and multifaceted. A study of the visitors to the City of London Cemetery shows that people refer to "three different "spirits" of the deceased, or possibly one "soul" with different "spirit" manifestations of "presence": one separated from the body and gone to heaven; one that is at the gravesite (their 'new home'); and one present 'all the time' or at people's homes (Francis et al., 2005: 123).

As we see, the location of deceased people relates not only to (partial containment in) real spaces, but also to imagined ones. Metaphors and images can play an important role, for instance, in the case of stillborn babies, as the following quote 
suggests: 'Just like the child, gnomes and stars are ambiguous. They are absent and present at the same time. They are close and far away. They are here and there. They are part of our time and space and they are not part of it' (Bleyen, 2010: 79, in MD).

\section{Traces of absence}

One argument that is only rather implicitly made in the two books reviewed here is what we could call the relational ontology of absence. We find some discussion that points in this direction, for instance the argument that 'personhood and identity emerge as relational, negotiated concepts that refer to spatially located practices' (Hockey et al., 2010: 227) or that we should think about materiality and immateriality as 'a spectrum of engagements and entrapments' (Meskell, 2010: 212, in AA). In other chapters we read about the 'connections', 'dialogues' or 'bonds' between the living and the dead. And most chapters contend that, in one way or another, absence goes with presence and that both stand in a mutual relationship. We might, therefore, talk about the relational ontology of absence. This is how John Law (2010: 272) defines relational ontology: "what there is in the world, social and natural, is an effect of uncertain and provisional relations of representation, political and scientific.' All material entities are produced in relations; what defines and makes them is their relational materiality. Bones, for instance, are such

relational entities, the forms and material properties of which are emergent through the interactions which take place with them ... they come to be defined and shaped within relations of various sorts - relations which can be at once material and social, emotional and political, and which develop and change over time. (Hallam, 2010: $467,468)$.

The challenge is, then, to use such an approach to explore the immaterial world as well. Essentially, this means to see absence not as an existing 'thing' in itself but as something that is made to exist through relations that give absence matter. It means seeing absence as something performed, textured and materialized through relations and processes. Thus, a second point to make is that, rather than talking about 'connections' between the absent and the present, perhaps a more fertile and less dualistic way of thinking is to conceive absence as a trace and as something that needs to be traced. Hetherington (2004: 162) reminds us that 'the absent is only ever moved along and is never fully gotten rid of' (emphasis in the original). So the question, both methodological and theoretical, becomes: how can we, as social scientists, trace absence? How do we follow and describe the movements, the attachments, the translations and representations through which absence becomes matter and through which absence comes to matter? The polysemic nature of the word 'trace' is appealing for our purpose here. For it denotes, first of all, an active and spatial act of drawing or mapping out something. Second, it means to find, locate, follow, trail, etc. Third, the noun 'trace' stands for a sign, a residue, a vestige. Tracing absence is thus at once a spatial and performative act; a movement that is always following and 'behind' its object and therefore unable to capture it fully; and, finally, a trace is something that points to, something that is incomplete, something that once was. These traces always lead us into other places, other directions, other times; they are always incomplete, elusive, slippery and awkward. 
Conceiving absence as a trace and as something that needs to be traced raises further thought about the relation between absence and geography. Hetherington (2003: 1941) has argued that 'the absent has a geography - a surrounding that implies both presence and present' (emphasis in original). The present discussion shows that we not only need to explore the multiple geographies of absence but also to examine the spaces that contain absence and how absence defies, escapes and moves within these spaces. In fact, we could summarize both $\mathrm{AA}$ and MD as books concerned with people's efforts to 'place absence' and the ambiguities and difficulties thereof. It is in his discussion about disposal that Hetherington (2004: 159) used the term 'placing', further noting that this term refers to both a spatial and a temporal category. He writes: "Terms like "waste disposal" and "waste management" are misnomers. Rather, disposal is about placing absences and this has consequences for how we think about "social relations" (emphasis in the original). Both books, in this sense, are concerned with the material culture and the productivity and consequences of 'placing absence'.

\section{Final remarks}

Throughout this essay, I have provided one possible reading of the two books (in relation to recent debates about absence) and highlighted two related sets of arguments: the materiality and agency of absence and the argument that absence is (to be) 'placed' and 'traced'. Of course, both books offer many more insights, debates and case studies than this essay was able to consider. They provide rich, detailed and engaging accounts for scholars interested in issues around materiality, death, absence, the body, bereavement, etc., whether they have a disciplinary background in archaeology, anthropology, history, sociology, or theology. Furthermore, both books show that the study of absence, loss and death can offer very stimulating insights, sometimes counterintuitive, at other times heart-breaking (and we cannot but imagine the painful research process behind most studies presented here). Rather than being a dry, uninteresting, immaterial object, absences are 'cultural, physical and social phenomena' (Bille et al., 2010: 4) and thus deserve academic scrutiny. It is now common to argue that we should not consider absence and presence as a dualism and that we should not strictly oppose the two. Both have agency; both are performative and have effects. But perhaps the time has come to move beyond such arguments. Rather than talking about presence and absent presence, we might for instance use terms such as 'propinquity' in order to talk about 'degrees of nearness in different registers, rather than presence ... Propinquity rather facilitates presence in terms of relation, analogy, nearness in time, or nearness of place' (Buchli, 2010: 186, in AA). In other words, we need to theorize about death, absence, presence, etc. through concepts and approaches that relate, that hold together the absent and the present.

Such relational approaches invite us to embrace absence and presence, materiality and immateriality, and to be symmetric: the effects and presences of both present and absent things can be similar. Yet this should not prevent us from recognizing that sometimes absence and presence can be very different things. A 'thing' like a chair or a human body can be very different from an 'immaterial thing' like the present absence of a dead person. An immaterial thing is less solid, less bounded, less complete, less 'presentable' than a thing. A 'thing' like a chair or a human body 
can more easily be 'held together' in one place, whereas an immaterial thing is, simply put, less coherent. Also, it is important to note that, when presence is turned into absence (a building destroyed, a person dying), we are faced with cuts, ruptures and irreversibilities. Even though the dead might have effects on and leave traces in people's social worlds, they cannot be brought back to life. A dead person, after all, 'does not talk back' (Hockey et al., 2010: 11). There are some things that dead bodies cannot perform.

Terms like 'dialogue with the dead' (MacConville and McQuillan, 2010: 207, in $\mathrm{MD}$ ) have therefore to be used with caution. First, there is a risk in stressing all too quickly that there are 'bonds', 'connections', 'communications' between the dead and the living, or between presences and absences. While, of course, such connections do exist, such a stance might blind us to see the very partial, distributed and heterogeneous nature of these bonds. These connections might only be present in certain places, at certain times, but not at others. Also, these connections are very much defined by separations and ruptures, that is, by disconnections. Perhaps our current concepts need to be enriched to better capture such 'connections with the disconnected' or 'dis/connections' and the processes through which absence is at once 'placed' and 'displaced'. (Hallam's, 2010, article about the relationality of bones also makes the point that both joinings and separations come into play to articulate bones.) Second, if we use a notion like 'dialogue with the dead' we need to be clear about what our notion of dialogue entails. For a 'dialogue with the dead' is most likely to be less verbal, less articulate, less 'in-between' (but rather 'through') entities, and less symmetrical than a dialogue between living persons. Yet, in fact, both books convincingly show that absence is far more than a discursive 'thing' in that it is performed through a material, technical and discursive assemblage. Thus, rather than seeking to reveal a dialogue 'with' or 'between' entities, the way forward, as both books demonstrate, is to map out all the places, metaphors and objects that do the 'talking'.

Recasting Mary Douglas's (1984: 35) famous definition of dirt as 'matter out of place', we might argue that, while absence is matter out of place, it is still placed through matter. Although, strictly speaking, absence is a thing without matter, absence is ordered, remembered, evoked and made discussable and sufferable through materialities. And even though absence escapes - and can only ever be partially and temporarily contained in - certain places, it is within these places and through leaving various kinds of traces that absence comes to matter.

\section{Acknowledgements}

The author would like to thank Paul Basu, Catherine Rémy and Martin Tironi for their comments and suggestions.

\section{References}

- Bille M (2010) Seeking providence through things: the word of God versus black cumin. In: Bille $\mathrm{M}$ et al. (eds) An Anthropology of Absence: Materializations of Transcendence and Loss. Berlin: Springer, 167-184. 
- Bille M, Hastrup F and Sørensen TF (eds) (2010) An Anthropology of Absence: Materializations of Transcendence and Loss. Berlin: Springer.

- Bleyen J (2010) The materialities of absence after stillbirth: historical perspectives. In: Hockey J et al. (eds) The Matter of Death: Space, Place and Materiality. Basingstoke: Palgrave Macmillan, 69-84.

- Buchli V (2010) Presencing the im-material. In: Bille M et al. (eds) An Anthropology of Absence: Materializations of Transcendence and Loss. Berlin: Springer, 185-206.

- Buchli V and Lucas G (2001) Presencing absence. In: Buchli V, Lucas G (eds) Archaeologies of the Contemporary Past. London: Routledge, 171-174.

- Davies DJ (2010) Geographies of the spirit world. In: Hockey J et al. (eds) The Matter of Death: Space, Place and Materiality. Basingstoke: Palgrave Macmillan, 208-222.

- Douglas M (1984) Purity and Danger. London: Ark.

- Fowles S (2010) People without things. In: Bille M et al. (eds) An Anthropology of Absence: Materializations of Transcendence and Loss. Berlin: Springer, 23-44.

- Francis D, Kellaher L and Neophytou G (2005) The Secret Cemetery. Oxford: Berg.

- Hallam E (2010) Articulating bones: an epilogue. Journal of Material Culture 15(4): 465-492.

- Hastrup F (2010) Materializations of disaster: recovering lost plots in a tsunamiaffected village in south India. In: Bille $M$ et al. (eds) An Anthropology of Absence: Materializations of Transcendence and Loss. Berlin: Springer, 99-114.

- Hetherington K (2003) Spatial textures: place, touch, and praesentia. Environment and Planning A 35(11): 1933-1944.

- Hetherington K (2004) Second-handedness: consumption, disposal and absent presence. Environment and Planning D: Society and Space 22(1): 157-173.

- Hockey J, Komaromy C and Woodthorpe K (eds) (2010) The Matter of Death: Space, Place and Materiality. Basingstoke: Palgrave Macmillan.

- Kellaher L, Hockey J and Prendergast D (2010) Wandering lines and cul-de-sacs: trajectories of ashes in the United Kingdom. In: Hockey $\mathrm{J}$ et al. (eds) The Matter of Death: Space, Place and Materiality. Basingstoke: Palgrave Macmillan, 133-147.

- Law J (2010) The Greer-Bush test: on politics in STS. In: Akrich M et al. (eds) Débordements: Mélanges offerts à Michel Callon. Paris: Presses des Mines, 269281.

- MacConville U and McQuillan R (2010) Potent reminders: an examination of responses to roadside memorial in Ireland. In: Hockey $\mathrm{J}$ et al. (eds) The Matter of Death: Space, Place and Materiality. Basingstoke: Palgrave Macmillan, 195-207.

- Meskell L (2010) An anthropology of absence: commentary. In: Bille M et al. (eds) An Anthropology of Absence: Materializations of Transcendence and Loss. Berlin: Springer, 207-214.

- Meyer M and Woodthorpe K (2008) The material presence of absence: a dialogue between museums and cemeteries. Sociological Research Online 13(5).

- Sørensen TF (2010) A saturated void: anticipating and preparing presence in contemporary Danish cemetery culture. In: Bille M et al. (eds) An Anthropology of Absence: Materializations of Transcendence and Loss. Berlin: Springer, 115-130.

- Walter T and Gittings C (2010) What will the neighbours say? Reactions to field and garden burial. In: Hockey J et al. (eds) The Matter of Death: Space, Place and Materiality. Basingstoke: Palgrave Macmillan, 165-177. 